\title{
IMPACT OF DIABETES MELLITUS ON MICROVASCULAR MYOCARDIAL PERFUSION AND LEFT VENTRICULAR REMODELING IN PATIENTS WITH ACUTE MYOCARDIAL INFARCTION TREATED WITH PRIMARY CORONARY INTERVENTION
}

\author{
By
Sameh Refaat Allam, El-Sayed Ali Abdo El-Marghany and Omar Ahmed Helmi \\ Cardiology Department, Al-Azhar Faculty of Medicine \\ E-mail: d.omarhelmy@gmail.com
}

\begin{abstract}
Background: Diabetes mellitus (DM) is associated with a greater risk of cardiovascular disease and almost one third of patients with acute myocardial infarction (AMI) may have undiagnosed DM on admission. DM is associated with abnormal endothelial function, increased inflammatory response, increased platelets and leukocytes plugging and seems to be an important factor deteriorating microvascular reperfusion in acute phase of MI.

Objective: The purpose of this study was to evaluate the impact of diabetes mellitus on: (1) Myocardial microvascular reperfusion after primary PCI in patients with acute myocardial infarction utilizing two well validated measures of myocardial reperfusion, resolution of ST- segment elevation and myocardial blush grade (MBG) and (2) Left ventricular systolic function recovery and incidence of remodeling after primary PCI in patients with acute myocardial infarction.
\end{abstract}

Patients and Methods: The study population consisted of 100 patients with STEMI (50 diabetic and 50 nondiabetic) conducted at coronary care unit of El-Zyton specialized hospital .All patients underwent Primary percutaneous coronary intervention (1ry PCI), ECG (pre and post PPCI) to assess ST segment resolution and Conventional 2D echocardiography to asses left ventricular ejection fraction ( LVEF) (by M-Mode and Simpson rule), end diastolic volume (EDV) and end systolic volume (ESV) and wall motion score index(WMSI) was done within $72 \mathrm{hr}$ of admission and after 3 months later and patients with $\mathrm{LV}$ remodeling, i.e. an increase $>20 \%$ in LV end-diastolic volume (LVEDV), were identified.

Results: No significant difference was found regarding baseline demographic, clinical and lab data except in dyslipidemic number of patients $(92 \%$ in diabetic group vs. $36 \%$ in non-diabetic group. There was a statistically significant difference between both studied groups as regard ECG post PPCI finding, no significant difference between 2 groups as regard baseline ECHO (EF by M-Mode, EF by Simpsons rule, LVEDV, LVESV, E/A ratio, deceleration time (DT) and wall motion score index). As regard coronary angiography and 1ry PCI data there was a significant difference between diabetic and non-diabetic group as regard number of diseased vessel and myocardial blush grade (MBG): $\mathrm{MBG}(0)$ was $1 \%$ in diabetic group and was $1 \%$ in non-diabetic group, MBG (1) was $12 \%$ in diabetic group and was $4 \%$ in non-diabetic group ,MBG(2) was $48 \%$ in diabetic group and was $14 \%$ in non-diabetic group and $\operatorname{MBG}(3)$ was $38 \%$ in diabetic group and was $80 \%$ in non-diabetic group . 
Conclusion: The microvascular reperfusion in STEMI patients with diabetes was worse than STEMI patients without diabetes. The incidence of remodeling was more in STEMI patients with diabetes than STEMI patients without diabetes.

Keywords: Acute coronary syndromes, Acute myocardial infarction, Antithrombotic therapy, Fibrinolysis, Ischemic heart disease, Primary percutaneous coronary intervention, Reperfusion therapy, ST-segment elevation.

\section{INTRODUCTION}

Cardiovascular disease (CVD) is the leading cause of morbidity and mortality among people with diabetes mellitus, who have a risk of cardiovascular mortality two to four times greater than that of people without diabetes.

Diabetes mellitus (DM) in patients after acute myocardial infarction (MI) has been shown to be a strong predictor of short-and long-term mortality .It has also been recognized that DM is associated with an increased rate of post-infarction heart failure (HF) (Preis et al.,2009).

The assessment of microvascular perfusion and integrity is integral for risk stratification in patients with AMI, especially after primary PCI, in whom TIMI-3 is restored in more than $90 \%$ of patients. In this regard, prior studies have demonstrated the prognostic utility of both ST segment resolution (STR) and MBG in this setting. The electrocardiographic STR has been shown to be related to cell membrane integrity and myocyte function. Conversely, the angiographic measure of MB reflects anatomic microvascular patency (Andrade et al., 2013).

Progressive HF after acute MI in nondiabetic patients is mainly related to left ventricular (LV) remodeling, which is a complex process influenced by multiple factors including micro vascular reperfusion (Lamblin et al .,2012).
The present study aimed to evaluate the impact of diabetes mellitus on myocardial reperfusion after primary PCI in patients with acute myocardial infarction utilizing, resolution of STsegment elevation and myocardial blush grade (MBG) and to evaluate the impact of diabetes mellitus on left ventricular remodelling using 2-D echocardiography.

\section{PATIENTS AND METHODS}

This study was a single centre, cross sectional, comparative study, conducted at coronary care unit of El-Zyton specialized hospital - Cairo - Egypt, during the period from October 2018 to May 2019. One hundred patients (50 diabetic patients and 50 non diabetic patients) with first attack STEMI treated by primary percutaneous coronary intervention (PCI) were enrolled in the study.

\section{Exclusion criteria:}

Patients with previous myocardial infarction, patients with ischemic cardiomyopathy, patients with previous CABG, conditions on ECG confounding the interpretation including left bundle branch block (LBBB), pacing and ectopy, patient with pervious PCI, patients with bad echo window or when complete echo study cannot be done, lost patients during the follow-up period, Rhythm other than sinus Rhythm, patients with significant valvular, myocardial or pericardial diseases and patient received pharmacological reperfusion therapy. 


\section{IMPACT OF DIABETES MELLITUS ON MICROVASCULAR MYOCARDIAL...}

All patients were subjected to the following: full history taking, complete general and local examination. Blood samples were taken upon admission for measure $\neg$ ment of blood creatinine level and ECG.

Echocardiography: Conventional transthoracic echocardiographic had been performed during the first 72 hrs of hospitalization and three months later. All patients were examined in left lateral position using (Philips, GE vivid S5-3 $\mathrm{MHz}$ transducers, China )

Global LV systolic function: The enddiastolic volume (EDV), end-systolic volume (ESV) and LV ejection fraction (EF) will be used to express the LV global systolic function. It was calculated from the apical two and/or four chamber 2-D study using modified Simpson method. LV remodeling was defined as a significant LV dilation (an increase in EDV $\geq 20 \%$ ) based on repeated measurements in individual patients (Lamblin et al., 2012).

\section{Diastolic function: Doppler} echocardiography was used to assess parameters of diastolic function including E/A ratio (early E-wave to late A-wave LV filling), E-wave deceleration time (DCT E) and isovolumetric relaxation time (IVRT). Diastolic dysfunction was diagnosed based on criteria defined by the European Study Group on Diastolic Heart Failure: IVRT > 92-105 ms; E/A ratio < 1-0.5; DCT E > 220-280 $\mathrm{ms}$ according to age in the presence of preserved LV systolic function (EF > 45\%) (Choe et al., 2017).
Reperfusion strategy: All the patients were subjected to reperfusion by PCI. All patients received Aspirin (300 mg), nitroglycerin infusion and oxygen supplementation when needed. Anticoagulation with unfractionated heparin was routinely given (80-100 unit/kg), and patients received Clopidogrel (loaded with $600 \mathrm{mg}$ at the opinion discretion, followed by $75 \mathrm{mg}$ per day) in addition to conventional treatment (Beta- blocker, nitrates, ACEI and statin). Right femoral artery puncture (using Seldinger's technique) was done. TIMI flow grade was evaluated from the baseline coronary angiogram and after the completion of coronary an $\neg$ gioplasty. Myocardial Blush Grade (MBG) was assessed, and Blush was graded according to dye density score: 0 - no myocardial blush or no persistent blush, 1 - minimal blush, 2 moderate blush but less that obtained during angiography of contralateral or ipsilateral non infarct-related artery, and 3 - normal myocardial blush (Gargiulo et al., 2016).

\section{Statistical analysis:}

Statistical presentation and analysis of the present study was conducted, using the mean, standard Deviation range, median and frequency. Analysis done by MannWhitney test, Independent samples Student's t-test, Chi-square test (Linearby-Linear association) and chi-square tests by (IBM SPSS Statistics for Windows, Version 20.0. Armonk, NY: IBM Corp.). P-value of $<0.05$ was considered statistically significant. 


\section{RESULTS}

This study was conducted prospectively on 100 (50 diabetic and 50 non diabetic) patients with STEMI subjected to primary PCI. The general

characteristics (risk factors, age and gender) of the patient population were set out in (Table 1).

Table (1): Comparative analysis between diabetic group and non-diabetic group in relation to demographic characteristics of study

\begin{tabular}{|c|c|c|c|}
\hline $\begin{array}{ll}\text { Parameters } & \text { Groups } \\
\end{array}$ & Diabetics & Non-diabetics & \multirow[t]{2}{*}{$\begin{array}{l}\text { P-value } \\
\text { (Sig.) }\end{array}$} \\
\hline Number & 50 & 50 & \\
\hline \multicolumn{4}{|l|}{ Risk factors } \\
\hline HTN & $42(84 \%)$ & $40(80 \%)$ & 0.603 \\
\hline Smoking & $29(58 \%)$ & $30(60 \%)$ & 0.839 \\
\hline Dyslipidemia & $46(92 \%)$ & $18(36 \%)$ & $<0.001$ \\
\hline Family history of IHD & $17(34 \%)$ & $20(40 \%)$ & 0.534 \\
\hline Age Mean \pm SD & $50.1 \pm 5.3$ & $48.2 \pm 6.9$ & 0.127 \\
\hline \multicolumn{4}{|l|}{ Gender } \\
\hline Male & $35(70 \%)$ & $40(80 \%)$ & \multirow[t]{2}{*}{0.248} \\
\hline Female & $15(30 \%)$ & $10(20 \%)$ & \\
\hline
\end{tabular}

Regarding MBG, there was a significant difference between diabetic and non-diabetic group: MBG (0) was 1 $\%$ in diabetic group versus $1 \%$ in nondiabetic group, MBG (1) was $12 \%$ in diabetic group versus $4 \%$ in non-diabetic group, MBG (2) was $48 \%$ in diabetic group versus $14 \%$ in non-diabetic group and MBG (3) was $38 \%$ in diabetic group versus $80 \%$ in non-diabetic group with $\mathrm{p}$ value (0.001) (Figure 1).

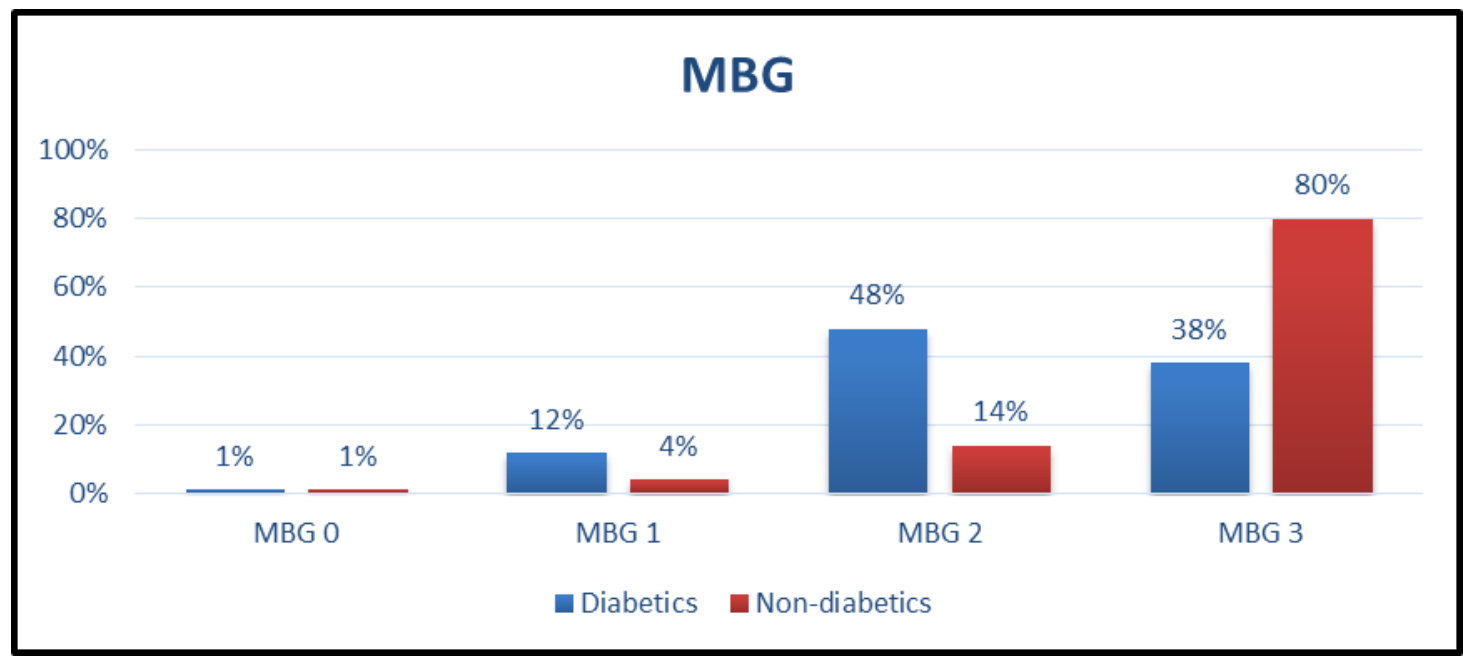

Figure (1): Comparative analysis between diabetic and non diabetic groups in relation to myocardial blush grade of study 


\section{IMPACT OF DIABETES MELLITUS ON MICROVASCULAR MYOCARDIAL...}

ST segment resolution after PPCI: Mean value of ST elevation after primary PCI was 4 (1-6) $\mathrm{mv}$ in diabetic group versus 3 (2-6) mv in non-diabetic group. ST segment resolution after primary PCI was $1.25(0-4) \mathrm{mv}$ in diabetic group versus $2.5(1-4) \mathrm{mv}$ in nondiabetic group (Figure 2).

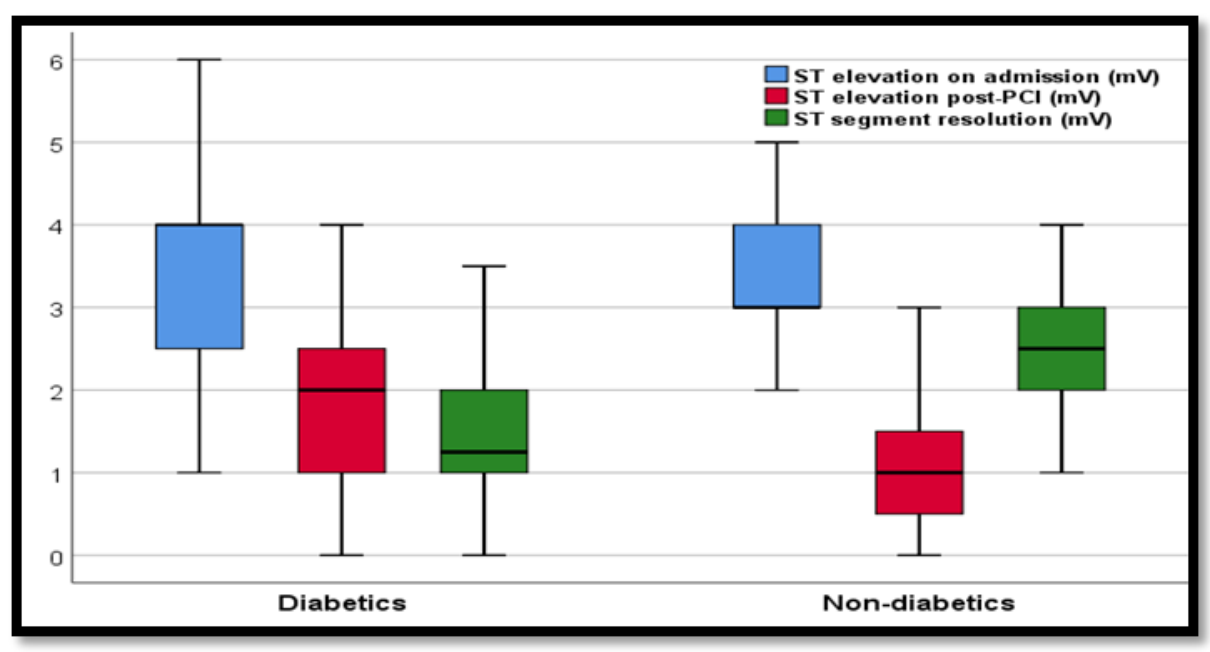

Figure (2): Comparative analysis between diabetic and non diabetic groups in relation to ECG resolution of study

Baseline echocardiographic assessment: difference between diabetic and non-diabetic There was no statistically significant patients at basic conventional echo (Table 2).

Table (2): Comparative analysis between diabetic and non-diabetic groups in relation to echocardiographic parameters basic post myocardial infarction

\begin{tabular}{|c|c|c|c|}
\hline $\begin{array}{ll}\text { Parameters } & \text { Groups } \\
\end{array}$ & Diabetics & Non-diabetics & \multirow[t]{2}{*}{$\begin{array}{c}\text { P-value } \\
\text { (Sig.) }\end{array}$} \\
\hline Number & 50 & 50 & \\
\hline \multicolumn{4}{|c|}{ EF by m-mode (\%) } \\
\hline Mean \pm SD & $52.6 \pm 6.0$ & $54.7 \pm 6.5$ & 0.088 \\
\hline \multicolumn{4}{|c|}{ EF by Simpson’s (\%) } \\
\hline Mean \pm SD & $47.3 \pm 8.5$ & $48.7 \pm 6.3$ & 0.341 \\
\hline \multicolumn{4}{|c|}{ LVEDD (mm) } \\
\hline Median (Range) & $54(34-65)$ & $55(40-65)$ & 0.748 \\
\hline \multicolumn{4}{|c|}{ LVESD $(\mathrm{mm})$} \\
\hline Median (Range) & $40(27-61)$ & $37(27-47)$ & 0.067 \\
\hline \multicolumn{4}{|c|}{ LVEDV $(\mathrm{mL})$} \\
\hline Mean \pm SD & $94.8 \pm 19.5$ & $101.4 \pm 19.6$ & 0.098 \\
\hline \multicolumn{4}{|c|}{ LVESV $(\mathrm{mL})$} \\
\hline Median (Range) & $45.5(22-89)$ & $47(32-87)$ & 0.139 \\
\hline \multicolumn{4}{|c|}{ E/A ratio } \\
\hline Median (Range) & $0.80(0.6-1.3)$ & $0.82(0.7-1.4)$ & 0.989 \\
\hline \multicolumn{4}{|c|}{ DCT E (ms) } \\
\hline Mean \pm SD & $217.8 \pm 64.9$ & $227.9 \pm 63.0$ & 0.431 \\
\hline \multicolumn{4}{|c|}{ WMSI } \\
\hline Median (Range) & $1.25(1.06-1.53)$ & $1.18(1.03-1.53)$ & 0.098 \\
\hline
\end{tabular}


Three months follow up groups as regards LVEDD, LVEDV, echocardiographic assessment showed LVESV, E/A ratio and DCT (ms) (Table no significant differences between the $2 \quad 3$ ).

Table (3): Comparison between diabetics and non-diabetics regarding the 3-month follow up echocardiographic data.

\begin{tabular}{|c|c|c|c|}
\hline Parameters & Diabetics & Non-diabetics & $\begin{array}{l}\text { P-value } \\
\text { (Sig.) }\end{array}$ \\
\hline Count & 50 & 50 & \\
\hline \multicolumn{4}{|l|}{ EF by m-mode (\%) } \\
\hline Median (Range) & $53(37-76)$ & $54.5(47-76)$ & 0.002 \\
\hline \multicolumn{4}{|l|}{ EF by Simpson's (\%) } \\
\hline Median (Range) & $48.5(30-63)$ & $52(37-65)$ & $<0.001$ \\
\hline \multicolumn{4}{|l|}{ LVEDD (mm) } \\
\hline Median (Range) & $55(30-69)$ & $55(40-65)$ & $0.076)$ \\
\hline \multicolumn{4}{|l|}{ LVESD (mm) } \\
\hline Median (Range) & $38.5(25-65)$ & $36(25-60)$ & 0.025 \\
\hline \multicolumn{4}{|l|}{ LVEDV (mL) } \\
\hline Median (Range) & $100(68-150)$ & $101(66-140)$ & 0.583 \\
\hline \multicolumn{4}{|l|}{ LVESV (mL) } \\
\hline Median (Range) & $50(33-81)$ & $50(29-73)$ & 0.144 \\
\hline \multicolumn{4}{|l|}{ E/A ratio } \\
\hline Median (Range) & $0.80(0.6-1.2)$ & $0.82(0.7-1.7)$ & 0.075 \\
\hline \multicolumn{4}{|l|}{ DCT E (ms) } \\
\hline Median (Range) & $216(82-395)$ & $216(106-361)$ & 0.444 \\
\hline \multicolumn{4}{|l|}{ WMSI } \\
\hline Median (Range) & $1.24(1.06-1.47)$ & $\begin{array}{lll}.15 & (1.00 & - \\
1.41) & & \\
\end{array}$ & $<0.001$ \\
\hline \multicolumn{4}{|l|}{ Incidence of remodeling } \\
\hline & $19(38 \%)$ & $8(16 \%)$ & 0.013 \\
\hline
\end{tabular}


There was a significant difference between the 2 groups as regard EF by Mmode: It was $53(37-76) \%$ in diabetic group versus $54.5(47-76) \%$ in non- diabetic group and EF by Simpsons rule was $48.5(30-63) \%$ in diabetic group versus $52(37-65) \%$ in non-diabetic group (Figure 3).

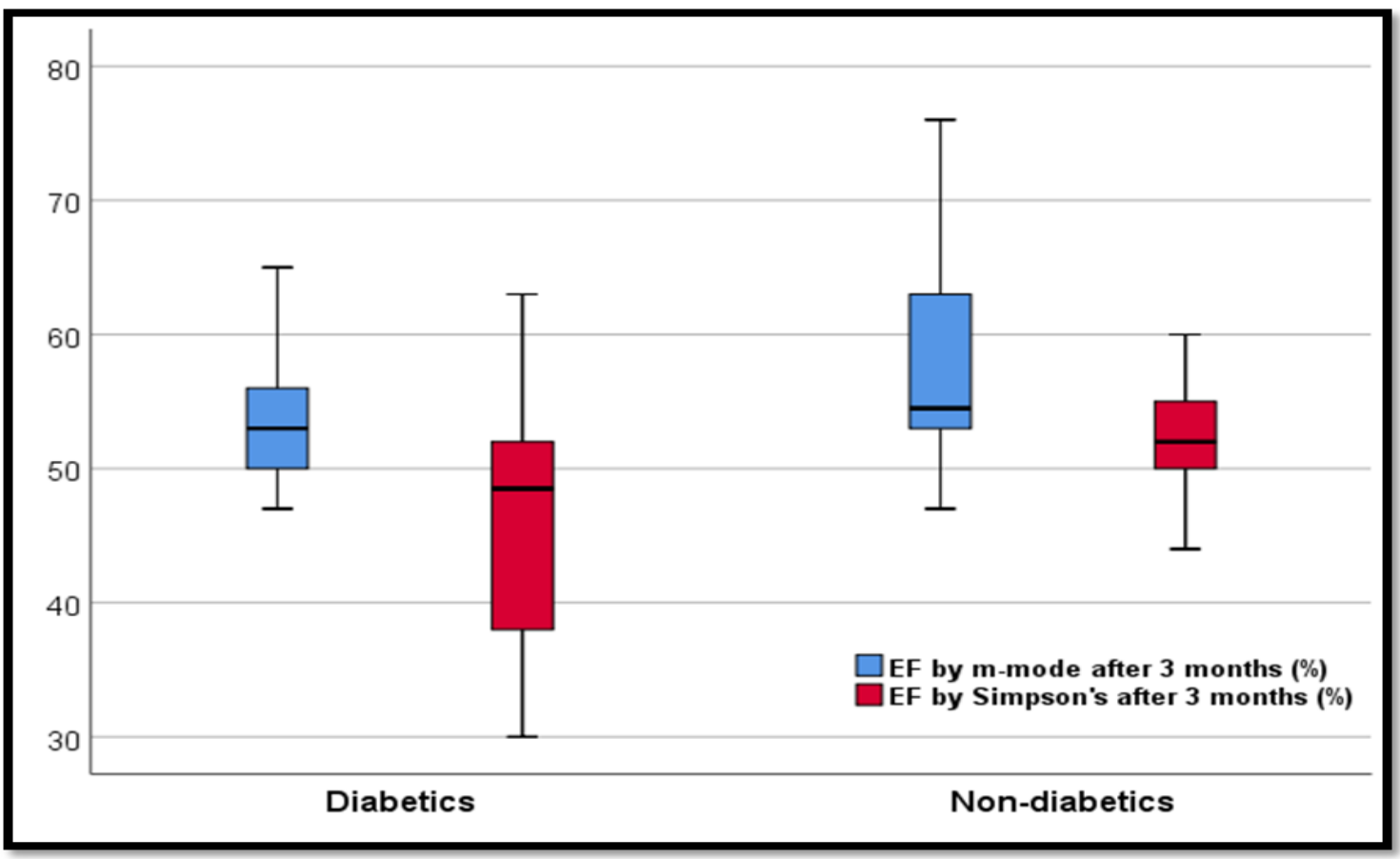

Figure (3): Comparison between diabetics and non-diabetics regarding the 3-month follow up EF by M-Mode and Simpson role.

There was a significant difference between diabetic and non-diabetic group as regard WMSI was 1.24(1.06-1.47) in diabetic group versus $1.15(1-1.41) \%$ in non-diabetic group LV remodeling was observed in $(38 \%)$ patients with DM versus $(16 \%)$ patients of the non-DM group (Figure 4).

\section{Incidence of remodelling}

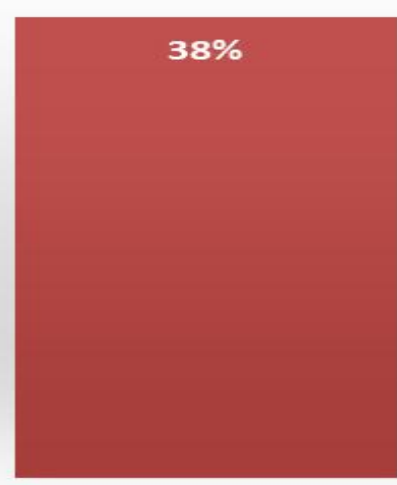

Diabetics

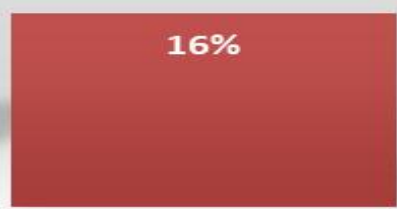

Non-diabetics

Figure (4): Comparative analysis between diabetic and non-diabetic groups regarding LV remodeling within three months of study 


\section{DISCUSSION}

There was no significant difference between diabetic and non-diabetic group regarding age and sex. There were 71 males (33 diabetic\& 38 non diabetic) and 29 females (17 diabetic\& 12 non diabetic) with a mean age of diabetic patients $54.60 \pm .77$ years and non-diabetic 55.56 \pm 9.87 which agreed with Araszkiewicz et al. (2014).

Regarding hypertension (HTN), family history and smoking there was no significant difference between diabetic and non-diabetic group which agree with Araszkiewicz et al. (2014) detected that no significant difference was found between diabetics and non-diabetics regarding baseline clinical characteristics.

Our results revealed that diabetic patients had impaired myocardial reperfusion after primary PCI in comparison to non-diabetic patients as measured by MBG .This was in agreement with Verouden et al. (2010) and Andrade et al.(2013) who compared myocardial reperfusion after successful primary PCI in patients with ST-elevation myocardial infarction versus non diabetic.Patients with diabetes mellitus were more frequently had reduced MBG and incomplete ST-segment resolution compared with non-diabetic patients .

Contrary to our results regarding to MBG data reported by Brener et al (2012) found that there were no differences in MBG between patients with and without DM. This was due to their wider study population.

Regarding ST segment resolution, there was significant difference between diabetic and non-diabetic group which was incomplete resolution $(<70 \%)$ in $70 \%$ of diabetics with complete resolution in $58 \%$ of non-diabetic patients. This was in agreement with Antoniucci et al. (2004) who studied the impact of diabetes mellitus on effectiveness of reperfusion and outcome of patients undergoing primary PCI for acute myocardial infarction.

There was no significant difference between two groups regarding baseline conventional 2D echo Doppler parameters (EF\%, LVEDV, LVESV, E/A ratio and deceleration time). This concordant with Araszkiewicz et al. (2014) and Amira et al. (2016) who found that there was no statistically significant difference between diabetic and non-diabetic patients as regarding LVEDV, LVESV, EF or WMSI. Also, Shah et al. (2011) demonstrated no difference in changes in $\mathrm{LV}$ volumes and LVEF from baseline to 1-month and from 1-month to 20-month follow up between patients with and without diabetes.

This was in disagreement with Georgette et al. (2015) who founded that after STEMI, diabetic patients showed more impaired LV EDV and WMSI. This may be due to different inclusion and exclusion criteria, wider study population and different demographic criteria.

There was a significant difference between diabetic and non-diabetic group regarding follow up echo parameters after 3 months (EF\% by M-Mode and Simpson rule, LVESD, WMSI). This was in agreement with Araszkiewicz et al. (2014) and Choe et al. (2017).

Also in our study, the estimated percentage of remodeling among all study population was $27 \%$ with significant 


\section{IMPACT OF DIABETES MELLITUS ON MICROVASCULAR MYOCARDIAL 157}

difference between diabetic and nondiabetic group. This was in disagreement with Araszkiewicz et al. (2014).This may be due to different inclusion and exclusion criteria and different demographic criteria.

\section{CONCLUSION}

The microvascular reperfusion in STEMI patients with diabetes was worse than STEMI patients without diabetes. The incidence of remodeling was more in STEMI patients with diabetes than STEMI patients without diabetes.

\section{LIMITATIONS}

There were some limitations in our study: First, it included a single medical center (El-Zyton specialized center). Second, small number of patients included in the study (100 patients). Third, our results cannot be directly extrapolated to other subgroup of patients, such as those treated with thrombolytic therapy.

\section{REFERENCES}

1. Amira M, Samy w and Randa A (2016): Speckle Tracking Echocardiography in Diabetic Patients with STEMI. Med. J. Cairo Univ,. 1579-1585.

2. Andrade $P$, Rinaldi $F$ and Bergonso $M$ (2013):.ST-Segment Resolution after Primary Percutaneous Coronary Intervention: Characteristics, Predictors of Failure, and Impact on Mortality. Rev Bras CardiolInvasiva, 21(3):227-33.

3. Antoniucci $D$, Valenti $R$ and Migliorini A(2004): Impact of Insulin-Requiring diabetes mellitus on effectiveness of reperfusion and outcome of patients undergoing primary percutaneous coronary intervention for acute myocardial infarction; American Journal of Cardiology, 93( 9):1170-1172.

4. Araszkiewicz A, Janus $M$ and Prech $M$ (2014): Relations of diabetes mellitus, microvascular reperfusion and left ventricular remodelling in patients with acute myocardial infarction treated with primary coronary intervention. Kardiol Pol., 72, 1: 20-26.

5. Brener SJ, Mehran $R$ and Dressler $O$ (2012): Diabetes mellitus, myocardial reperfusion, and outcome in patients with acute ST-elevation myocardial infarction treated with primary angioplasty (from HORIZONS AMI). Am J Cardiology, 109(8):1111-6.

6. Choe J, Cha $K$ and Yun EY (2017): Reverse Left Ventricular Remodelling in STElevation Myocardial Infarction Patients Undergoing Primary Percutaneous Coronary Intervention: Incidence, Predictors, and Impact on Outcome.Heart Lung Circ., 27(2):154-164.

7. Farag $E$ and Al-Daydamony $M$ (2017): Symptom-to-balloon time and myocardial blush grade are predictors of left ventricular remodelling after successful primary percutaneous coronary intervention. Cardiovasc J, 28: 186-190.

8. Gargiulo G (2016): 6- or 24-month dualantiplatelet therapy duration: Insights from the PROlonging Dual-antiplatelet treatment after grading stent-induced Intimal hyperplasia studY trial. Am Heart J, 174:95102.

9. Georgette E, Rachid A and Joyce E (2015): Comparison of Changes in Global Longitudinal Peak Systolic Strain after STSegment Elevation Myocardial Infarction in Patients with Versus Without Diabetes Mellitus. Am J Cardiol., 116:1334-9.

10. Lamblin $\mathbf{N}$, Fertin $M$ and de Groote $P$ (2012): Cardiac remodeling and heart failure after a first anterior myocardial infarction in patients with diabetes mellitus. J Cardiovasc Med (Hagerstown), 13: 353-359.

11. Preis S, Hwang $S$ and Coady Sa (2009): Trends in all-cause and cardiovascular disease mortality among women and men with and without diabetes mellitus in the Framingham Heart Study, 1950 to 2005. Circulation, 119(13): 1728-35. 
12. Shah AM, Hung CL and Shin SH (2011): Cardiac structure and function, remodeling, and clinical outcomes among patients with diabetes after myocardial infarction complicated by left ventricular systolic dysfunction, heart failure, or both. Am Heart J., 162:685-91.
13. Verouden NJ, Haeck JD and Kuijt WJ (2010): Clinical and angiographic predictors of ST-segment recovery after primary percutaneous coronary intervention, American Journal of Cardiology, 105(12):1692-1697 


\title{
IMPACT OF DIABETES MELLITUS ON MICROVASCULAR MYOCARDIAL...
}

\section{تأثير مرض السكرى على إعادة التروية القلبية و إعادة بنية

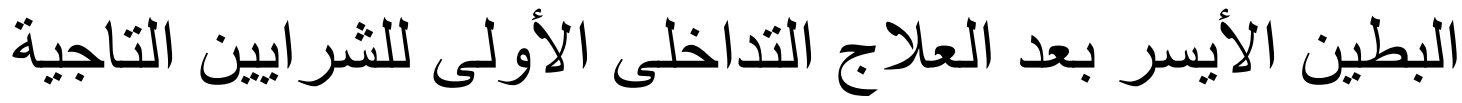

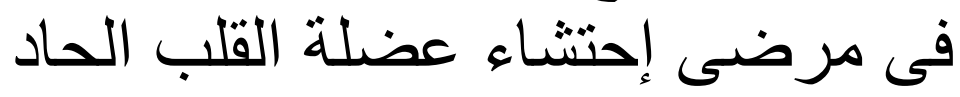

\author{
سامح رفعت علام، السبد علي عبده المرغني، عمر أحمد حلمي عبد الرحمن \\ قسم القلب، كليه طب الأزهر
}

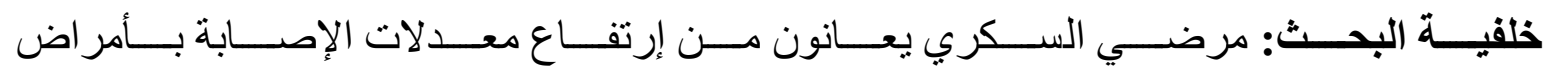

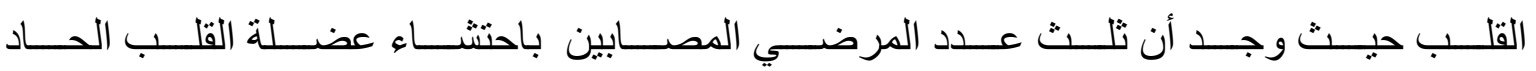

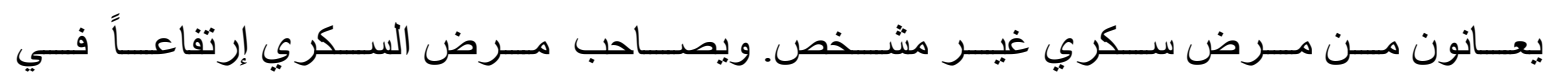

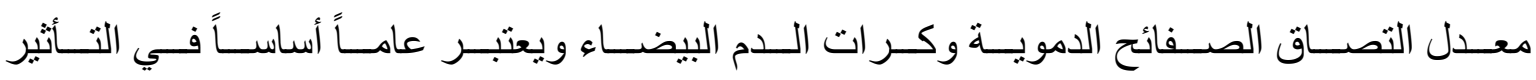
علي إعادة التروية القلبية بعد إحتشاء عضلة القلب الحادئ

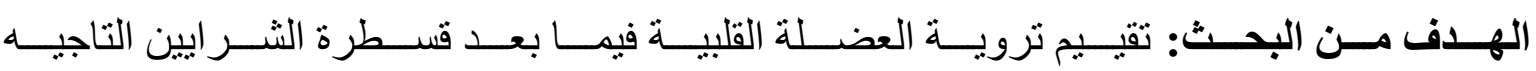

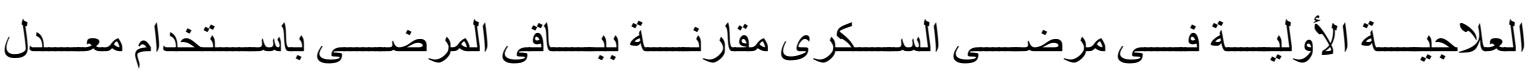

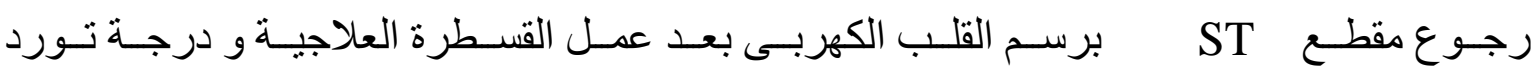

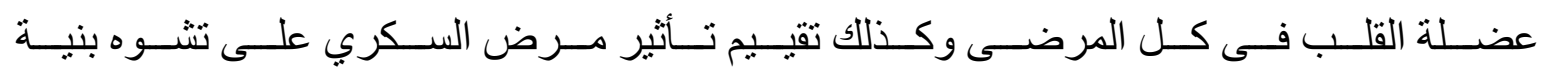

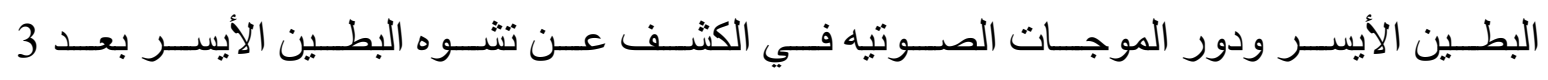
اشهر من اجر اء قسطرة الثر ايين التاجية العلاجية الاولية.

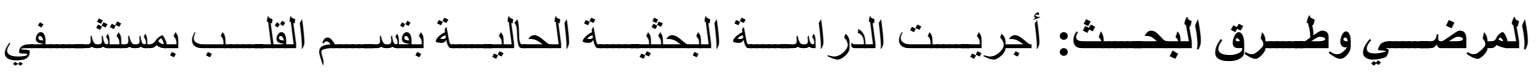

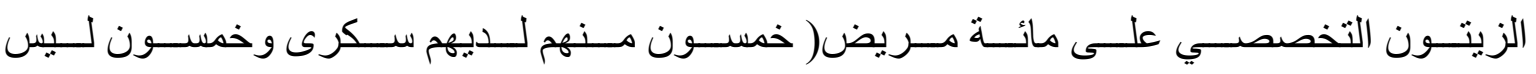

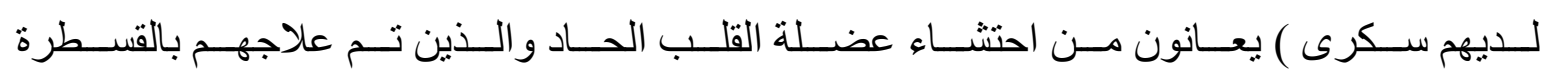
العلاجية الأولية فى الفترة من شهر اكتوبر 2018 حتى شهر مايو 2019

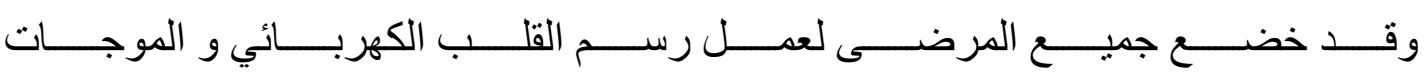

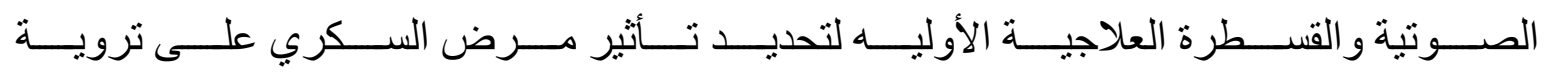
عضلة القلب وتثنوه بنية البطين الأيسر.

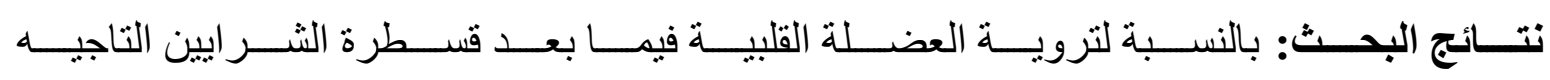

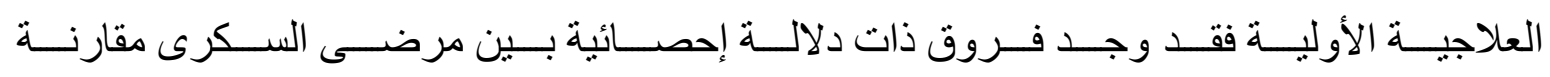




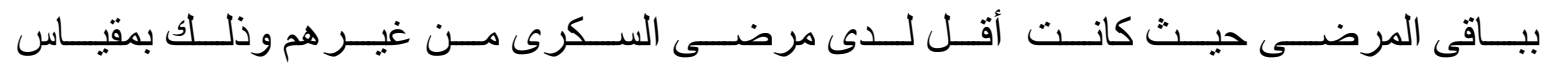

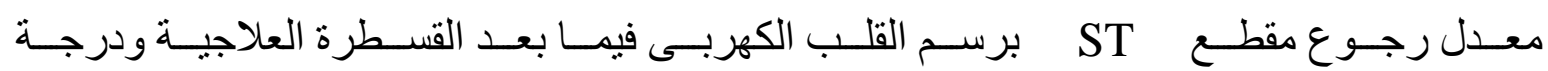

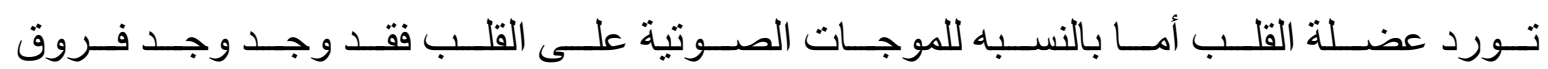

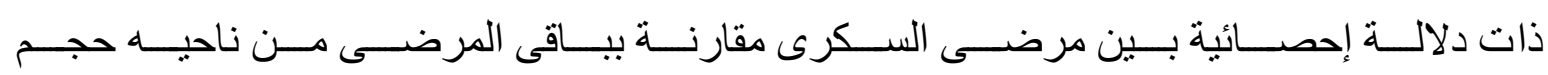

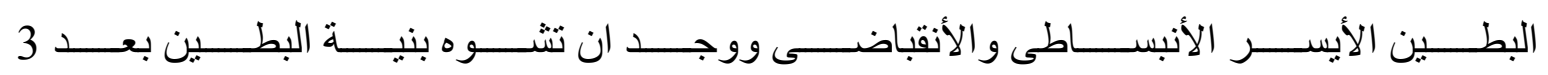

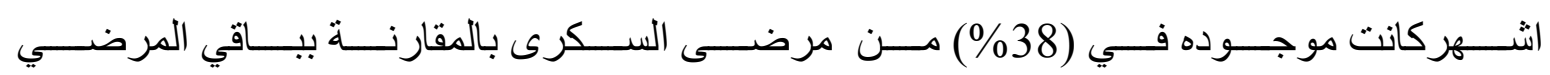
حيث كانت موجوده في (16\%).

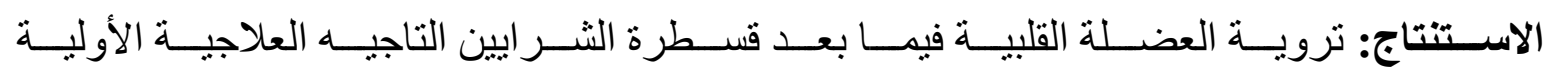

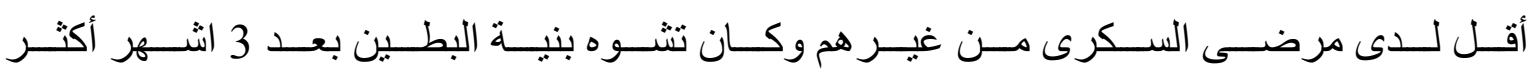
لاى مرضى السكرى من غير هم. 